\title{
The iterates of positive linear operators with the set of constant functions as the fixed point set
}

\author{
TEOdora CĂTINAŞ ${ }^{1}$, DiAnA Otrocol ${ }^{2}$ and IOAN A. Rus ${ }^{1}$
}

\section{ABSTRACT.}

Let $\Omega \subset \mathbb{R}^{p}, p \in \mathbb{N}^{*}$ be a nonempty subset and $B(\Omega)$ be the Banach lattice of all bounded real functions on $\Omega$, equipped with sup norm. Let $X \subset B(\Omega)$ be a linear sublattice of $B(\Omega)$ and $A: X \rightarrow X$ be a positive linear operator with constant functions as the fixed point set. In this paper, using the weakly Picard operators techniques, we study the iterates of the operator $A$. Some relevant examples are also given.

\section{REFERENCES}

[1] Agratini, O., Approximation by linear operators, Cluj University Press, 2001 (in Romanian)

[2] Agratini, O. and Rus, I. A., Iterates of a class of discrete linear operators via contraction principle, Comment. Math. Univ. Caroline, 44 (2003), 555-563

[3] Agratini, O. and Rus, I. A., Iterates of some bivariate approximation process via weakly Picard operators, Nonlinear Analysis Forum, 8 (2003), No. 2, 159-168

[4] Altomare, F. and Campiti, M., Korovkin-type Approximation Theory and its Applications, de Gruyter Studies in Mathematics, 17, Walter de Gruyter \& Co., Berlin, 1994

[5] András, S. and Rus, I. A., Iterates of Cesáro operators, via fixed point principle, Fixed Point Theory 11 (2010), No. 2, 171-178

[6] Bohl, E., Linear operator equations on a partially ordered vector space, Aeq. Math., 4 (1970), fas. 1/2, 89-98

[7] Cristescu, R., Ordered vector spaces and linear operators, Abacus Press, 1976

[8] Gavrea, I. and Ivan, M., The iterates of positive linear operators preserving the constants, Appl. Math. Lett., 24 (2011), No. 12, 2068-2071

[9] Gavrea, I. and Ivan, M., On the iterates of positive linear operators, J. Approx. Theory, 163 (2011), No. 9, 1076-1079

[10] Gavrea, I. and Ivan, M., Asymptotic behaviour of the iterates of positive linear operators, Abstr. Appl. Anal., 2011, Art. ID 670509, 11 pp.

[11] Gavrea, I. and Ivan, M., On the iterates of positive linear operators preserving the affine functions, J. Math. Anal. Appl, 372 (2010), No. 2, 366-368

[12] Gonska, H., Piţul, P. and Raşa, I., Over-iterates of Bernstein-Stancu operators, Calcolo, 44 (2007), 117-125

[13] Heikkila, S. and Roach, G. F., On equivalent norms and the contraction mapping principle, Nonlinear Anal., 8 (1984), No. 10, 1241-1252

[14] Rasa, I., Asymptotic behaviour of iterates of positive linear operators, Jaen J. Approx., 1 (2009), No. 2, 195-204

[15] Rus, I. A., Generalized contractions and applications, Cluj Univ. Press, 2001

[16] Rus, I. A., Iterates of Stancu operators, via contraction principle, Studia Univ. Babeş-Bolyai Math., 47 (2002), No. 4, 101-104

[17] Rus, I. A., Iterates of Bernstein operators, via contraction principle, J. Math. Anal. Appl., 292 (2004), No. 1, $259-261$

[18] Rus, I. A., Iterates of Stancu operators (via contraction principle) revisited, Fixed Point Theory, 11 (2010), No. 2, 369-374

Received: 28.01.2015; In revised form: 18.11.2015; Accepted: 25.11.2015

2010 Mathematics Subject Classification. 47H10, 46B42, 47B65.

Key words and phrases. Banach lattice, iterates of an operator, linear operator, linear and positive operator, linear fixed point partition, fixed point, weakly Picard operator.

Corresponding author: Diana Otrocol; dotrocol@ictp.acad.ro 
[19] Rus, I. A., Fixed points and interpolation point set of a positive linear operator on $C(\bar{D})$, Studia Univ. Babeş-Bolyai, Math., 55 (2010), No. 4, 243-248

[20] Rus, I. A., Heuristic introduction to weakly Picard operators theory, Creative Math. Inf., 23 (2014), No. 2, 243-252

[21] Rus, I. A., Iterates of increasing linear operators, via Maia's fixed point theorem, Stud. Univ. Babeş-Bolyai Math., 60 (2015), No. 1, 91-98

[22] Stancu, D. D., On some generalization of Bernstein polynomials, Studia Univ. Babeş-Bolyai Math., 14 (1969), No. 2, 31-45 (in Romanian)

\author{
1 Department of Mathematics \\ BABEŞ-BOLYAI UNIVERSITY \\ M. KOGĂLNiCEANU 1, RO-400084 CluJ-NAPOCA, ROMANIA \\ E-mail address: tcatinas@math.ubbcluj.ro \\ E-mail address: iarus@math.ubbcluj.ro \\ 2 Tiberiu POPOVICIU InSTITUte OF NUMERICAL ANALYSIS, ROMANIAN ACADEMY \\ FÂNTÂNELE 57, 400110 ClUJ-NAPOCA, ROMANIA \\ E-mail address: dotrocoleictp.acad.ro
}

